\title{
Protecting healthcare workers: A critical part of the COVID-19 response
}

In the past 8 months, over 7000 healthcare workers (HCWs) worldwide have died as a result of COVID-19. ${ }^{[1]}$ In addition, a substantial number of healthcare work hours have been lost as a result of SARS-CoV-2-related illness or downtime due to presumed infection. ${ }^{[2]}$ The cost of occupationally acquired infection to health systems everywhere will continue to mount until an effective preventive intervention is found. Reliance on non-pharmaceutical measures, especially personal protective equipment such as N95 respirators and latex gloves, has been the protective mainstay so far. While not all infections in HCWs have been acquired in the clinic, it is clear that workplace infection control measures have fallen short of comprehensive protection. ${ }^{[3,4]}$

The global outpouring of gratitude to the frontline healthcare workforce underscores the concern and respect reserved for HCWs and is reminiscent of the anxieties and concerns three decades ago at the beginning of the HIV epidemic. ${ }^{[5]}$ Once the HIV virus was isolated and described, it became clear that universal precautions with regard to handling of body fluids were required. ${ }^{[6]}$ Furthermore, special precautions were required around high-risk clinical interventions such as postmortem procedures and certain surgeries. With the advent of antiviral agents, especially zidovudine, the first postexposure prophylaxis for accidental occupational exposure was devised and adopted into practice. ${ }^{[7]}$ This was feasible because accidental exposure to blood through needlestick and surgical injury was a well-defined event.

Exposure to airborne infections is more challenging to prevent and harder to recognise. The nature of SARS-CoV-2 transmission, the type of exposure, and the most advisable protective equipment have been discussion topics since the COVID-19 pandemic struck. ${ }^{[8]}$ The majority of SARS-CoV-2 transmission takes place from presymptomatic and asymptomatic people, and from environmental sources; asymptomatic transmission and asymptomatic disease can make the exposure event difficult to pinpoint. For these reasons, it is important to find potential pre-exposure prevention interventions to provide additional safeguards, especially among HCWs whose work places them at high risk.

A COVID-19 pre-exposure prophylaxis drug or alternative intervention is urgently needed to mitigate this risk. The successful candidate will need to have a proven safety profile, and be easy to administer and easy to take. To stimulate the search for such a candidate, the COVID-19 Therapeutics Accelerator, the COVID19 Research Outcomes Worldwide Collaborative (CROWN COLLABORATIVE), has initiated a Bayesian platform trial called CROWN CORONATION in seven countries in Africa, Europe and North America (NCT04333732). ${ }^{[9]}$ While existing drugs with antiviral properties are being considered for investigation, compelling observational data have emerged suggesting benefit from administration of the measles, mumps and rubella (MMR) vaccine or other existing vaccines. ${ }^{[10]}$ Epidemiological and clinical studies have shown that vaccines employing live attenuated micro-organisms such as BCG, measles-containing vaccines, and oral polio vaccine may exert heterologous protective effects against other unrelated infections, which are not necessarily a result of specific $\mathrm{T}$ - or B-cell responses. They rather invoke a phenomenon called 'trained immunity. ${ }^{[11,12]}$
An unpublished, observational, propensity-matched analysis of data from the Mayo Clinic has shown that recent receipt of MMR vaccine (within 5 years) is associated with $\sim 50 \%$ reduced risk of SARS-CoV-2 infection. ${ }^{[13]}$ Causality cannot be inferred from these data, however, and there is sufficient rationale for conducting a rigorous clinical trial to answer whether the MMR vaccine does have benefit as an immuneboosting intervention to decrease the incidence and/or severity of SARS-CoV-2 infection. Further, it may bolster the immune response to subsequent immunisation with a specific SARS-CoV-2 vaccine. Should this safe, inexpensive and simply administered intervention work, it would also present options for rapid and efficient scale-up, while waiting for other more specific interventions. Specific vaccine development is currently underway, with a number of candidates and regimens already in efficacy trials, but there are no guarantees of efficacy until the studies are complete. In the event of efficacy and licensure, many millions of vaccine doses will be needed worldwide, with logistic challenges including manufacture scale-up and global distribution.

The CROWN CORONATION study specifically considers HCWs, who are particularly vulnerable to SARS-CoV-2 owing to repeated contacts with infected patients, as well as exposure to patients with high viral loads. There is broader potential for public health impact if effectiveness is proven and use were to be extended to hairdressers, waiters, flight attendants, grocers, and others at high risk as they stand at the economic and social frontlines. Beyond the current pandemic, demonstrating the effectiveness of nonspecific protection conferred by a live attenuated vaccine provides security against the next novel pathogen with pandemic potential.

\section{L-G Bekker}

Desmond Tutu HIV Centre, Department of Medicine, Faculty of

Health Sciences, University of Cape Town, South Africa

linda-gail.bekker@hiv-research.org.za

\section{S Delany-Moretlwe}

Wits Reproductive Health and HIV Institute, Faculty of Health Sciences, University of the Witwatersrand, Johannesburg, South Africa

\section{B Biccard, L duToit}

Department of Anaesthesia and Perioperative Medicine, Groote Schuur Hospital and Faculty of Health Sciences, University of Cape Town, South Africa

\section{B Lovat}

Division of Surgery and Interventional Science, University College London, UK

\section{H-M Dehbi}

Comprehensive Clinical Trials Unit at UCL University College London, UK

\section{R Moonesinghe}

National Institute for Academic Anaesthesia, Health Services Research Centre and Associate National Clinical Director for Elective Care, National Health Service, UK 


\section{H Rees}

Wits Reproductive Health and HIV Institute, Faculty of Health Sciences, University of the Witwatersrand, Johannesburg, South Africa

\section{S Avidan}

Washington University, St Louis, USA

1. Amnesty International. Global: Amnesty analysis reveals over 7,000 health workers have died from COVID-19. 3 September 2020. https://www.amnesty.org/en/latest/news/2020/09/amnesty-analysis7000-health-workers-have-died-from-covid19/ (accessed 20 September 2020).

2. Cachero P. Medical workers risk exposing themselves to the coronavirus, and now they're self-isolating from their families to protect them, too. Insider, 7 April 2020. https://www.insider.com/medicalworkers-self-isolation-treating-covid-19-coronavirus-2020-4 (accessed 20 September 2020).

3. Nguyen LH, Drew DA, Graham MS, et al. Risk of COVID-19 among front-line health-care workers and the general community: A prospective cohort study. Lancet Public Health 2020;5(9):e475-e483. https://doi.org/10.1016/S2468-2667(20)30164-X

4. Seto WH, Tsang D, Yung RW, et al. Effectiveness of precautions against droplets and contact in prevention of nosocomial transmission of severe acute respiratory syndrome (SARS). Lancet
a prevention of nosocomial transmission of severe acute respiratory synd

5. Bellani M, Furlani F, Gnecchi M, Pezzotta P, Trotti EM, Bellotti GG. Burnout and related factors among HIV/AIDS health care workers. AIDS Care 1996;8(2):207-221. https://doi. org/10.1080/09540129650125885
6. World Health Organization. Prevention of HIV transmission in clinical settings. 2007. https://www. who.int/hiv/pub/toolkits/HIV\%20transmission\%20in\%20health\%20care\%20setttings.pdf (accessed 20 September 2020).

7. Avert. Emergency HIV treatment (PEP) fact sheet. Last updated 14 April 2020. https://www.avert.org/ learn-share/hiv-fact-sheets/emergency-treatment (accessed 20 September 2020).

8. Koh WC, Naing L, Rosledzana MA, et al. What do we know about SARS-CoV-2 transmission? A systematic review and meta-analysis of the secondary attack rate, serial interval, and asymptomatic infection. medRxiv 2020 (epub 23 May 2020). https://doi.org/10.1101/2020.05.21.20108746

9. Crown Coronation Trial. https://www.crowncoronation.com/ (accessed 20 September 2020).

10. Higgins JPT, Soares-Weiser K, Reingold A. Systematic review of the non-specific effects of BCG, DTP and measles containing vaccines. 2014. https://www.who.int/immunization/sage/meetings/2014/april/3 NSE_Epidemiology_review_Report_to_SAGE_14_Mar_FINAL_pdf (accessed 20 September 2020).

11. Netea MG, Giamarellos-Bourboulis EG, Domínguez-Andrés J. Trained immunity: A tool for reducing susceptibility to and the severity of SARS-CoV-2 infection. Cell 2020;181(5):969-977. https://doi. org/10.1016/j.cell.2020.04.042

12. Mantovani A, Netea MG. Trained innate immunity, epigenetics, and Covid-19. N Engl J Med 2020;383:1078-1080. https://doi.org/10.1056/NEJMcibr2011679

13. Pawlowski $\mathrm{C}$. Puranik $\mathrm{A}$, Bandi $\mathrm{H}$. Exploratory analysis of immunization records highlights decreased PaRS-CoV-2 rates in individuals with recent non-COVID-19 vaccinations. medRxiv 2020 (epub
Salo 29 July 2020). https://doi.org/10.1101/2020.07.27.20161976

S Afr Med J 2020;110(12):1154-1155. https://doi.org/10.7196/SAMJ.2020.v110i12.15048 